\title{
DAumier E o SilÊNCIO DE BAudelaire
}

\section{Daumier and Baudelaire's silence}

\author{
Alexandre Ragazzi*
}

A amizade entre Honoré Daumier (1808-1879) e Charles Baudelaire (1821-1867) remonta à década de 1840 , quando artista e poeta eram vizinhos em Quai d'Anjou. É prova dessa amizade, por exemplo, a frustrada tentativa empreendida por Baudelaire de catalogar a obra litográfica de Daumier: Certa vez eu quis, junto com Daumier, fazer o catálogo completo de sua obra (BAUDELAIRE, 1976, p. 555). ${ }^{1}$ Outro fato, a visita feita por Baudelaire e Poulet-Malassis ao ateliê do pintor, a 14 de janeiro de 1852, a qual revela uma certa familiaridade entre os dois quando Poulet-Malassis diz:Baudelaire me leva à casa de Daumier em quai d'Anjou (...) (Archives du Louvre, dossier Moreau-Nélaton. In: MARCEAU; ROSEN, 1948, p. 80). Sabe-se dessa visita graças aos apontamentos de Poulet-Malassis; nenhum outro registro restou, mas não há por que supor que relações dessa espécie não fossem freqüentes. Também há um registro de 1858-9; em uma carta de Baudelaire endereçada a Adolphe Le Maréchal se lê: Estou na Île Saint-Louis, na casa de Daumier, que esteve à beira da morte por esses dias, e faço companhia à sua esposa (BAUDELAIRE, 1973, T. 1, p. 534-535). ${ }^{2}$ Finalmente, o poema feito por Baudelaire para reverenciar o amigo: ${ }^{3}$

* $\quad$ Mestre em História da Arte pelo Instituto de Filosofia e Ciências Humanas (IFCH) da Universidade Estadual de Campinas (Unicamp) Une fois j'ai voulu, avec Daumier, faire le catalogue complet de son ouvre.

Je suis dans l'île Saint-Louis, chez Daumier, qui a failli mourir ces jours-ci, et je tiens compagne à sa femme.

3 Esse poema, escrito em maio de 1865, atendeu a um pedido de Champfleury, que o queria para ilustrar a primeira edição de sua História da caricatura moderna. O poema acompanha uma gravura feita a partir de um relevo de Michel Pascal (1828-1882), a qual representa o rosto de Daumier em perfil (cf. CHAMPFLEURY, 1878, p. 64-65). 
Aquele de quem te oferecemos a imagem,

E cuja arte, sutil entre todas,

Ensina-nos a rir de nós mesmos,

Aquele, leitor, é um sábio.

É um satírico, um zombador;

Mas a energia com a qual

Ele pinta o Mal e sua seqüela

Prova a beleza de seu coração.

Seu riso não é a contorção do rosto

De Melmoth ou de Mefisto

Sob a tocha de Alecto

Que os queima, mas que nos gela ${ }^{4}$.

O riso deles, infelizmente, da alegria

Não é mais que a monstruosa charge;

o seu irradia, franco e largo,

Como um sinal de sua bondade.

(BAUDELAIRE, 1975, p. 167)

Como se percebe, é uma amizade acompanhada de um imenso respeito.

Baudelaire fez questão de demonstrar sua admiração por Daumier sobretudo o caricaturista Daumier - em diversos textos, desde 1845 até 1865. Há a comparação a Delacroix (1798-1863) feita no Salão de 1845 - Em Paris conhecemos apenas dois homens que desenham tão bem quanto o senhor Delacroix. Um de uma maneira análoga, o outro por um método contrário. Um é o senhor Daumier, o caricaturista; o outro o senhor Ingres, o grande pintor, o astuto admirador de Raffaello (BAUDELAIRE, 1976, p. 356) ${ }^{6}$-; o

4 Essa estrofe pode ser mais bem compreendida se se considerar o comentário do próprio Baudelaire que acompanhava o poema, enviado a 25 de maio de 1865 a Champfleury: "Eu quis dizer que o gênio satírico de Daumier não possuía nada em comum com o gênio satânico (...)" (BAUDELAIRE, 1973, T. II, p. 502). Alecto, uma das Fúrias, é a violenta divindade do canto VI da Eneida encarregada de vigiar um criminoso no círculo mais temível dos infernos; ela tem como arma uma tocha. Melmoth é o personagem do romance satânico-noir de C. R. Maturin, Melmoth the wanderer (Edimburgo, 1820).

5 Celui dont nous t'offrons l'image, / Et dont l'art, subtil entre tous, / Nous enseigne à rire de nous, / Celui-là, lecteur, est un sage. // C'est un satirique, un moqueur; / Mais l'énergie avec laquelle / Il peint le Mal et sa séquelle / Prouve la beauté de son cour. // Son rire n'est pas la grimace / De Melmoth ou de Méphisto / Sous la torche d'une Alecto / Qui les brûle, mais qui nous glace. // Leur rire, hélas! de la gaîté / N'est que la monstrueuse charge; / Le sien rayonne, franc et large, / Comme un signe de sa bonté.

$6 \quad$ Nous ne connaissons, à Paris, que deux hommes qui dessinent aussi bien que $M$. Delacroix, l'un d'une manière analogue, l'autre dans une méthode contraire. L'un est M. Daumier, le caricaturiste; l'autre, M. Ingres, le grand peintre, l'adorateur rusé de Raphaël. 
reconhecimento da memória inteligente de Daumier no Salão de 1846, no capítulo sobre o chic e o poncif (Ibid., p. 468); o tributo feito em Alguns caricaturistas franceses (Ibid., p. 549-557) - a maior parte do texto é dedicada a Daumier -; o elogio no início do Salão de 1859, em que Daumier, um dos poucos artistas dignos de conversar com um filósofo ou um poeta, é separado dos outros artistas, das crianças mimadas - Daumier é dotado de um bom senso luminoso que colore toda sua conversação (Ibid., p. 611); além das passagens em Escola pagã (Ibid., p. 46), em $O$ pintor da vida moderna, do poema de 1865 e de um artigo perdido - o qual era dedicado exclusivamente a Daumier. ${ }^{8}$ Sabe-se que Baudelaire, principalmente quando quer criticar um grupo - como os burgueses, os proletários ou os artistas -, recorre a várias ambigüidades e contradições; entretanto, quando seu objeto é uma pessoa específica ele sempre se mostra direto e incisivo. Há dois métodos para se fazer uma crítica severa: pela linha curva, e pela linha reta-que é o caminho mais curto (Ibid., p. 16). ${ }^{9}$ Daumier é um dos poucos que jamais receberam sequer uma única linha de reprovação por parte de Baudelaire.

Fato que chama a atenção é não se encontrar referência alguma de Baudelaire quanto à pintura ou à escultura de Daumier. Dolf Oehler diz que Baudelaire aparentemente pouco conheceu o pintor Daumier (OEHLER, 1997, p. 218), mas essa afirmação não parece ser verdadeira. Além das ligações entre os dois há pouco consideradas, pode-se lembrar uma vez mais a visita de 14 de janeiro de 1852 :

Baudelaire me leva [Poulet-Malassis] à casa de Daumier em quai d'Anjou. (...) Ele também é escultor. (...) Vejo como que uma grande bacanal em cera na parede do ateliê. Diversos esboços. Uma Madalena, uma lavadeira que arrasta uma pequena menina ao longo do quai contra um forte vento. (Archives du Louvre, dossier Moreau-Nélaton. In: MARCEAU; ROSEN, 1948, p. 80.) (Cf. LOYRETTE, 1999 , p. 554) ${ }^{10}$

$7 \quad$ Daumier est doué d'un bon sens lumineux qui colore toute sa conversation.

8 Por volta de 1861, Louis Martinet (1814-1895), diretor do recém fundado Courrier Artistique, teria se amedrontado diante da censura do governo de Luís Napoleão e se recusado a publicar o texto de Baudelaire. Em uma carta não datada, Baudelaire lamenta a não publicação do artigo; ao final da mesma, ele diz: "Tenha a bondade de guardar meus originais, não tenho cópias" (cf. BAUDELAIRE, 1973, T. II, p. 176). Ao que parece, Martinet não teve o zelo que os originais mereciam. le plus court chemin.

Il y a deux méthodes d'éreintage: par la ligne courbe, et par la ligne droite, qui est

10 Baudelaire me mène chez Daumier quai d'Anjou. (...) Il fait aussi de la sculpture. (...) Je vois comme une grande bacchanale en cire aux murs de l'atelier. Diverses ébauches. Une Madeleine, une blanchisseuse traînant une petite fille le long du quai par un grand vent. 
Também se sabe, por intermédio de André Quaintenne, de uma carta enviada a Daumier por Arthur Stevens, a 26 de setembro de 1864, na qual este pedia ao pintor que lhe enviasse a pintura Um vagão de terceira classe: Meu amigo Baudelaire, que se encontra, assim como eu, momentaneamente na Bélgica, acaba de me informar que viu, há algum tempo em vosso ateliê, um quadro que representa Uma viagem de terceira classe (...) (In: DAUMIER, 1948, p. 95). ${ }^{11}$ Portanto, Baudelaire conhecia, muito bem, tanto a pintura quanto a escultura de Daumier. $O$ fato de ele permanecer em silêncio não pode ser visto como desconhecimento, indiferença ou reprovação de sua parte. $O$ que significa esse silêncio é o que se considerará no decorrer deste ensaio. ${ }^{12}$

A crítica baudelairiana estabelece certos atributos específicos indispensáveis para o artista que se pretenda digno para assumir o papel de pintor da vida moderna. Baudelaire deseja que esse artista extraia a beleza que há no mal, que utilize a lei dos contrastes e que encontre o eterno que há no transitório. ${ }^{13}$

Quando Baudelaire diz, no poema citado há pouco sobre Daumier, que a energia com a qual Daumier pinta o Mal e sua seqüela prova a beleza de seu coração, então basta passar os olhos, ainda que rapidamente, sobre a obra de Daumier para se ter uma idéia do que o crítico-poeta quer caracterizar como o Mal. Seja no contexto do poema sobre Daumier, seja no título de sua própria obra - As flores do mal -, com a palavra mal Baudelaire se refere aos seus contemporâneos, à sociedade burguesa originada em 1789 e fortalecida após 1830. O homem moderno é o seu alvo, é o Mal, e é desse mal que ele pretende extrair a beleza.

A lei dos contrastes, que governa a ordem moral e a ordem fisica (BAUDELAIRE, 1976, p. 19), ${ }^{14}$ é talvez o ponto mais importante para se compreender tanto a crítica quanto a poesia de Baudelaire. Sem isso em mente, corre-se o risco de se interpretar Baudelaire às avessas. A célebre dedicatória do Salão de 1846 - Aos burgueses - (Ibid., p. 415-417), a passagem do mesmo Salão em que Baudelaire diz experimentar um imenso prazer ao

11 Mon ami Baudelaire qui se trouve, ainsi que moi, momentanément en Belgique, m'apprend à l'instant qu'il a vu, ily a quelques temps, dans votre atelier, un tableau représentant Un voyage en troisième classe.

12 Poderia se objetar que Daumier expôs apenas em períodos em que Baudelaire não se ocupou da crítica dos Salóes - entre 1848 e 1851 e em 1861. Não obstante, sabe-se que Baudelaire elogia Rousseau (1812-1867) no Salão de 1846 (BAUDELAIRE, 1976, p. 484) e Préault (1809-1879) no Salão de 1859 (Ibid., p. 680), e isso apesar da ausência desses artistas naqueles Salões.

13 Em meio ao riquíssimo universo da estética baudelairiana, esses são os pontos que mais se prestam a esta argumentação.

14 (...) la loi des contrastes, qui gouverne l'ordre moral et l'ordre physique (...). 
ver um policial espancar um republicano (Ibid., p. 490), ou ainda poemas como Abel e Caim (BAUDELAIRE, 1975, p. 122-123) e Aniquilemos os pobres! (Ibid., p. 357-359) são apenas alguns dos exemplos que apontam para uma intencionada descontinuidade do pensamento do autor. Se nos poemas o verdadeiro objetivo é percebido no final da leitura, as ambições de Baudelaire em seus textos críticos apenas são notadas com uma visão mais ampla e, sobretudo, se forem consideradas a ironia e as idéias complementares sugeridas pelo que foi escrito. Por não compreender isso é que muitos consideraram essas passagens como pró-burguesas. Nos Paraísos artificiais, quando escreve sobre as Confissões de um comedor de ópio inglês (1821), de Thomas de Quincey (1785-1859), Baudelaire diz que duas idéias que estão em relação de antagonismo chamam-se reciprocamente, e uma sugere a outra (BAUDELAIRE, 1975, p. 487). ${ }^{15}$ Um belo dia de verão evoca a idéia de morte; o vermelho sugere o verde; às vezes, uma reverência deve ser vista como um insulto e um golpe desferido por um punho cerrado é um sinal de ajuda. O segundo termo da analogia, oculto, pode não ser notado por alguns, mesmo pela maioria, mas, como será visto adiante, Baudelaire acredita que essa é a única solução possível para aquele artista que, embora ciente que não deva se deixar levar por uma arte pedagógica, tampouco queira renunciar totalmente ao mundo material.

No Salão de 1846, quando comenta o heroísmo da vida moderna, Baudelaire diz que todas as belezas contêm, como todos os fenômenos possíveis, alguma coisa de eterno e alguma coisa de transitório, de absoluto e de particular (BAUDELAIRE, 1976, p. 493). ${ }^{16}$ No ensaio sobre o pintor da vida moderna ele retoma essa afirmação - O belo é feito de um elemento eterno, invariável, cuja quantidade é excessivamente dificil de se determinar, $e$ de um elemento relativo, circunstancial (...) (Ibid., p. 685) ${ }^{17}$ - e a desenvolve para justificar sua estética sobre o esboço, a pintura instantânea e a moda. A dupla eterno-transitório se funde para compor a beleza, e o dever do artista é encontrar o eterno no transitório. Isso é mais facilmente percebido quando se analisa o retorno da moda. Baudelaire diz que $o$ passado, retendo o essencial do fantasma, retomará a luz e o movimento da vida e se fará presente (Ibid., p. 684). ${ }^{18}$ Esse fantasma, eterno, coexiste

15 D'ailleurs, deux idées qui sont en rapport d'antagonisme s'appellent réciproquement, et l'une suggère l'autre.

16 Toutes les beautés contiennent, comme tous les phénomènes possibles, quelque chose d'éternel et quelque chose de transitoire, - d'absolu et de particulier.

17 Le beau est fait d'un élément éternel, invariable, dont la quantité est excessivement difficile à déterminer, et d'un élément relatif, circonstanciel (...).

18 Le passé, tout en gardant le piquant du fantôme, reprendra la lumière et le mouvement de la vie, et se fera présent. 
com o transitório, efêmero, e os verdadeiros artistas são aqueles capazes de percebê-lo e de representá-lo em sua obra.

Sem dúvida, Delacroix foi o artista mais reverenciado por Baudelaire, e a fantasia - a imaginação - é a característica desse artista mais apreciada pelo crítico. É a fantasia que une Delacroix a Michelangelo (1475-1564), a Rubens (1577-1640), a Rembrandt (1606-1669). Delacroix éo infinito no finito, é o sonho! (Ibid., p. 636). ${ }^{19}$ Para Baudelaire, Delacroix definiu, melhor que qualquer outro, o invisivel, o impalpável, o sonho, os nervos, a alma (...) (Ibid., p. 744). ${ }^{20}$ Para tanto, valeu-se de um dos atributos essenciais do pintor da vida moderna, a rapidez na execução: É evidente que a seus olhos [aos olhos de Delacroix] a imaginação era o dom mais precioso, a faculdade mais importante, mas que essa faculdade permaneceria impotente e estéril se ela não possuísse a seu serviço uma habilidade rápida que pudesse seguir a grande faculdade despótica em seus caprichos impacientes (Ibid., p. 747). ${ }^{21}$ Delacroix possui tudo isso, é certo, mas, na visão de Baudelaire, falta-lhe a escolha do tema. No Salão de 1859 Baudelaire diz: jamais posso considerar a escolha do tema como indiferente e, apesar do amor necessário que deve fecundar a mais modesta tela, acredito que o tema faça parte do gênio para o artista, e, para mim, bárbaro apesar de tudo, parte do prazer (Ibid., p. 668). ${ }^{22}$ Delacroix, que pintara a casaca preta em 1830 - A liberdade guiando o povo -, logo renunciou à vida contemporânea e se entregou exclusivamente à fantasia. Apesar de a fantasia ser imprescindível, o tema também desempenha uma importante função. Era preciso alguém que pintasse o que Balzac (1799-1850) escrevia.

Em um artigo de 1862, Pintores e aquafortistas, Baudelaire assim se refere a Delacroix: Toda a glória da Escola francesa, durante vários anos, pareceu se concentrar em um só homem (...), cujas fecundidade e energia, o quão grandes que sejam, não são suficientes para nos consolar da pobreza do resto (Ibid., p. 737). ${ }^{23}$ Delacroix sozinho não é suficiente, e a opção proposta pelo realismo irrita profundamente Baudelaire. Courbet (1819-1877) é aproximado a Ingres (1780-1867) - no texto sobre a Exposição Universal de

19 C'est l'infini dans le fini. C'est le rêve!

20 C'est l'invisible, c'est l'impalpable, c'est le rêve, c'est les nerfs, c'est l'âme (...).

${ }_{21}$ Il est évident qu'à ses yeux l'imagination était le don le plus précieux, la faculté la plus importante, mais que cette faculté restait impuissante et stérile, si elle n'avait pas à son service une habileté rapide, qui pût suivre la grande faculté despotique dans ses caprices impatients.

22 Vous voyez, mon cher ami, que je ne puis jamais considérer le choix du sujet comme indifférent, et que, malgré l'amour nécessaire qui doit féconder le plus humble morceau, je crois que le sujet fait pour l'artiste une partie du génie, et pour moi, barbare malgré tout, une partie du plaisir.

23 Toute la gloire de l'École française, pendant plusieurs années, a paru se concentrer dans un seul homme (ce n'est certes pas de M. Ingres que je veux parler) dont la fécondité et l'énergie, si grandes qu'elles soient, ne suffisaient pas à nous consoler de la pauvreté du reste. 
1855 - justamente pela falta de imaginação (cf. Ibid., p. 585), e a falta de imaginação é o pior que pode haver segundo a concepção de Baudelaire. Ele diz ter escutado de Delacroix que a natureza é apenas um dicionário ${ }^{24}$ (Ibid., p. 624, 747); ${ }^{25}$ logo, o grande problema dos artistas realistas é não compreender a natureza como uma referência, mas sim como um modelo rígido. Para o artista, não se trata de copiar, mas de interpretar a natureza em uma língua mais simples e mais luminosa (Ibid., p. 457). ${ }^{26}$ É por isso que a arte de Courbet não merece a aprovação de Baudelaire, do mesmo modo que a arte do jovem Manet (1832-1883). ${ }^{27}$

Ainda mais malvista aos olhos de Baudelaire é a arte com explícitos fins didáticos. Sem o contraste, a ambigüidade e a contradição, a obra pedagógica conduz mais à acomodação do que à revolta. Portanto, é natural que Baudelaire se mostre tão enfático ao refutar a obra de Millet (1814-1875):

Seus camponeses são pedantes que possuem uma opinião demasiadamente alta sobre si mesmos. Exibem uma maneira de embrutecimento sombrio e fatal que me desperta o desejo de odiálos. Que trabalhem na colheita, que semeiem, que façam pastar as vacas, que tosem os animais, têm sempre o ar de dizer: "Pobres deserdados deste mundo, entretanto somos nós que o fecundamos! Nós cumprimos uma missão, nós exercemos um sacerdócio!" No lugar de extrair simplesmente a poesia natural de seu sujeito, o senhor Millet quer, a todo custo, acrescentar a ele alguma coisa. Em sua monótona fealdade, todos esses pequenos párias têm uma pretensão filosófica, melancólica e rafaelesca. (Ibid., p. 585) ${ }^{28}$

24 Cf. BAUDELAIRE, 1976, p. 717: "Quem ousaria conferir à arte a estéril função de imitar a natureza?"

25 La nature n'est qu'un dictionnaire.

26 Il ne s'agit pas pour lui (o artista) de copier, mais d'interpréter (a natureza) dans une langue plus simple et plus lumineuse.

${ }_{27}$ Cabe ressaltar que, em 1866, quando a doença de Baudelaire se agravou, Manet havia pintado menos de 70 quadros de uma obra que chegaria a quase 700 . As primeiras obras de Manet não agradaram a Baudelaire, e certamente tampouco mereceram sua aprovação Le déjeuner sur l'herbe (1863) ou a Olympia (1865) "- Que poeta ousaria, na pintura do prazer causado pela aparição de uma beleza, separar a mulher de seu traje?” (BAUDELAIRE, 1976, p. 714). Entretanto, não há porque supor que o restante da produção obtivesse o mesmo julgamento. Ao contrário, é bastante provável que muitas das obras de Manet, posteriores a 1867, fossem muito bem recebidas por Baudelaire.

28 Ses paysans sont des pédants qui ont d'eux-mêmes une trop haute opinion. Ils étalent une manière d'abrutissement sombre et fatal qui me donne l'envie de les haïr. Qu'ils moissonnent, qu'ils sèment, qu'ils fassent paître des vaches, qu'ils tondent des animaux, ils ont toujours l'air de dire: "Pauvres déshérités de ce monde, c'est pourtant nous qui le fécondons! Nous accomplissons une mission, nous exerçons un sacerdoce!" Au lieu d'extraire simplement la poésie naturelle de son sujet, M. Millet veut à tout prix y ajouter quelque chose. Dans leur monotone laideur, tous ces petits parias ont une prétention philosophique, mélancolique et raphaélesque. 
Baudelaire despreza a corrente de esquerda, em voga à época, que se contenta em elogiar o povo, em fazê-lo sentir-se digno e heróico. Para ele, a obra de significado pronto, imediato, que não depende nem da vontade nem do esforço de interpretação do público, essa espécie de obra não tem qualquer poder de ação. A partir disso, apresenta-se a possibilidade de se efetuar uma distinção entre a arte pura - que de modo algum deve ser compreendida como algo sem intenções sócio-políticas - e a arte filosófica - ingênua e estéril:

O que é a arte pura segundo a concepção moderna? É criar uma magia sugestiva que contenha ao mesmo tempo o objeto e o sujeito, o mundo exterior ao artista e o próprio artista.

o que é a arte filosófica segundo a concepção de Chenavard ${ }^{29}$ e da escola alemã? É uma arte plástica que tem a pretensão de substituir o livro, ou seja, de rivalizar com a imprensa para ensinar a história, a moral e a filosofia. (Ibid., p. 598) ${ }^{30}$

Muitas vezes se disse que Daumier fez com o trabalhador da cidade o que Millet fez com o trabalhador do campo. Entretanto, as obras de Daumier não apresentam simplesmente pessoas heróicas; com aqueles homens e mulheres robustos sente-se um grande sofrimento duramente suportado e uma profunda melancolia. A analogia com o pintor de Barbizon é fruto de obras como A revolta (The Phillips Collection - Washington), em que, ao contrário, presencia-se o sofrimento que não se conteve. Apesar da melancolia também contida nessa pintura, temas como esse certamente desapontam Baudelaire. Suas explícitas intenções pouco fazem pelo proletariado e, quanto à burguesia, esta ou se vê amedrontada, ou se vê tomada pelo ódio. É preciso fazer com que o público se esforce para compreender a obra e seu significado. É preciso unir a fantasia de Delacroix, o mundo contemporâneo e o contraste.

No ensaio $O$ pintor da vida moderna, Baudelaire faz o elogio de Constantin Guys (1802-1892). A escolha desse ilustrador - pouco conhecido entre os franceses de então - como o arquétipo do pintor da vida moderna é,

29 Paul-Marc-Joseph Chenavard (1807-1895) era amigo de Baudelaire (cf. BAUDELAIRE, 1976, p. 611), mas sua pintura pedagógica era a antítese do que ambicionava o crítico.

30 Qu'est-ce que l'art pur suivant la conception moderne? C'est créer une magie suggestive contenant à la fois l'objet et le sujet, le monde extérieur à l'artiste et l'artiste lui-même. Qu'est-ce que l'art philosophique suivant la conception de Chenavard et de l'école allemande? C'est un art plastique qui a la prétention de remplacer le livre, c'est-à-dire de rivaliser avec l'imprimerie pour enseigner l'histoire, la morale et la philosophie. 
a um só tempo, uma provocação e uma confissão sincera. Para Baudelaire Guys é um homem do mundo, um convalescente, uma criança curiosa, um dândi - e, como todo dândi, um indiferente -, um homem que seria um filósofo se não fosse tão apegado às coisas materiais, um moralista pitoresco, um observador. Na obra de Guys, encontram-se o oficial em traje de gala, os homens e as mulheres vestidos conforme a última moda, a maquilagem. Além do sujeito apropriado, Guys desenha com rapidez, com fantasia, de memória! Em suas composições estão representados alguns dos temas de Balzac com a fantasia de Delacroix.

Assim como Guys, Daumier também desenha de memória. Ele tem uma memória maravilhosa e quase divina que toma o lugar do modelo (Ibid., p. 556). ${ }^{31} \mathrm{Com}$ o medo de não ir suficientemente rápido, de deixar escapar o fantasma antes que a sintese tenha sido extraida e alcançada (Ibid., p. 699), ${ }^{32}$ essa espécie de artista - a espécie de Guys e Daumier utiliza um método segundo o qual, a qualquer estágio que se contemple a obra, ela apresenta um aspecto acabado; um esboço se se quiser, mas um esboço perfeito (Ibid., p. 700). ${ }^{33}$ Em vão se procurará em Daumier o lugar comum, a memória condicionada da mão sem reflexão. Ao contrário, ele medita profundamente. Com um pouco de imaginação, é possível vê-lo no terraço do apartamento de Quai d'Anjou, fumando seu cachimbo e refletindo sobre o que foi visto durante o dia. ${ }^{34}$ Toda essa reflexão faz com que ele hesite muitas vezes e se diga insatisfeito. Como o próprio Daumier confidenciou a Poulet-Malassis, na visita de 14 de janeiro de 1852, recomeço tudo 25 vezes, e, ao final, faço tudo em dois dias (In: LOYRETTE, 1999, p. 554). ${ }^{35}$ A respeito dessa insatisfação, que se lembre de Delacroix, que em seu diário, a 5 de fevereiro de 1849, menciona uma visita de Baudelaire, o qual o surpreendera no momento em que repintava uma figura de mulher à oriental: Ele (Baudelaire) me falou das dificuldades que Daumier experimenta em acabar (DELACROIX, 1963, p. 65). ${ }^{36}$ Quanto ao colorido, mesmo nas gravuras em preto e branco ele está presente. Os grandes coloristas sabem criar a impressão do colorido com um traje negro, uma gravata branca $e$

Il a une mémoire merveilleuse et quasi divine qui lui tient lieu de modèle.

32 (...) la peur de n'aller pas assez vite, de laisser échapper le fantôme avant que la synthèse n'en soit extraite et saisie (...).

33 (...) une ébauche si vous voulez, mais ébauche parfaite.

34 Quanto ao hábito de fumar, é oportuno lembrar o inusitado comentário de Préault: "O tabaco torna as coisas mais pesadas. (...) se Daumier não tivesse fumado, ele teria sido um grande pintor" (CLARETIE, 1882, p. 302). Esse é apenas mais um elemento que demonstra a incompreensão dos contemporâneos de Daumier em relação à sua obra - e isso vindo de um de seus amigos mais próximos.

35 Je recommence toute 25 fois, à la fin je fais tout en deux jours.

36 Il m'a parlé des difficultés qu'éprouve Daumier à finir. 
um fundo cinza (BAUDELAIRE, 1976, p. 495). ${ }^{37}$ Graças à experiência do início da carreira com os bustos-charges, ${ }^{38}$ Daumier adquiriu um profundo conhecimento de luz e sombra, o que faz com que ele se ligue à linhagem dos pintores adeptos da iluminação artificial, como Tintoretto (1518-1594) e Rembrandt (cf. FOCILLON, 1957, p. 110). Além de todos esses atributos, Daumier conhece como poucos a alma da burguesia. Do pequeno-burguês a Luís Filipe, o Rei-burguês, nada dessa classe escapou a seus olhos. Sobretudo - mas não exclusivamente - se se pensar em sua obra gráfica, não há quem corresponda melhor à Comédia humana de Balzac (cf. FOCILLON, 1969, p. 147). ${ }^{39}$

Tal qual acontece com Baudelaire no poema Os sete anciãos (BAUDELAIRE, 1975, p. 87-88), Daumier também tem suas fantasmagorias que retornam para assombrá-lo. Que imagem poderia representar melhor o artista atormentado do que o errante cavaleiro Dom Quixote tantas vezes pintado por Daumier? As pessoas de justiça são demônios que o assombram, enquanto que o fardo, A lavadeira, os boêmios, as pessoas nos vagões de terceira classe e $O$ f fugitivos $^{40}$ são fantasmas não à espera da condenação, mas da salvação. A cada nova aparição desses fantasmas, uma nova obra.

É Walter Benjamin (1892-1940) (1994, p. 111-112) quem chama a atenção para o poema $O \mathrm{Sol}$, de Baudelaire. Trata-se de um raro momento, em que o poeta descreve a si mesmo em meio a seu processo criativo:

Ao longo dos subúrbios, onde nos pardieiros Persianas acobertam beijos sorrateiros, Quando o impiedoso sol arroja seus punhais Sobre a cidade e o campo, os tetos e os trigais,

\footnotetext{
${ }_{37}$ Les grands coloristes savent faire de la couleur avec un habit noir, une cravate blanche et un fond gris.

${ }_{38}$ Série de bustos de personalidades políticas encomendada por Charles Philipon (1806-1862) no início de 1832 e utilizada por Daumier como modelo para realizar os retratoscharges - litografias publicadas nos jornais La Caricature e Le Charivari entre 1832 e 1833.

39 Assim, poderia se argumentar que bastava a Daumier traduzir para a pintura e a escultura o conteúdo de sua obra gráfica para corresponder aos anseios de Baudelaire. Nada poderia ser mais falso. Na concepção do crítico, o jornal, suporte da obra gráfica, permite a sátira, enquanto que a pintura e a escultura não aceitam esse gênero.

40 Les gens de justice (LD 1337 a 1375) é uma série publicada por Daumier entre 1845 e 1848; sob o título de Le fardeau agrupam-se sete variações executadas por Daumier sobre o tema além de uma escultura em argila (RAGAZZI, 2004, p. 128-129); as lavadeiras, os boêmios e as pessoas em vagóes são todos temas recorrentes do universo de Daumier; os Fugitifs - também conhecido como Émigrants - são variações feitas por Daumier - além de um desenho e quatro pinturas há ainda as duas peças em gesso feitas a partir de um original em argila - sobre o tema daqueles que estão sempre a procura de algo (Ibid., p. 74-85).
} 
Exercerei a sós a minha estranha esgrima, Buscando em cada canto os acasos da rima, Tropeçando em palavras como nas calçadas, Topando imagens desde há muito já sonhadas. (BAUDELAIRE, 1975, p. 83) ${ }^{41}$

O poeta se vê sozinho, esgrimindo contra a realidade da periferia da cidade, onde vivem os boêmios e onde tudo falta. Desse encontro, desse choque entre o poeta e o mundo, o que era vil tornou-se nobre. O poema termina assim:

Quando, tal como um poeta, [o sol] desce à cidade, Ele enobrece a sorte das coisas mais vis, E entra como um rei, sem ruído e sem criados, Em todos os hospitais e em todos os palácios.

(BAUDELAIRE, 1975, p. 83) ${ }^{42}$

Benjamin também nota quando o poeta fala a respeito de seu pintor da vida moderna: à hora em que os outros dormem, o pintor está esgrimindo com seu lápis, sua pena, seu pincel (BAUDELAIRE, 1976, p. 693). O que Benjamin qualifica como a experiência do choque, determinante na obra de Baudelaire, pode ser aplicado a toda a obra de Daumier. O pintor diante de sua tela é um tema tardio em Daumier - acredita-se que ambas as versões tenham sido pintadas entre 1865 e $1875 .{ }^{43}$ A obra representa um pintor na penumbra do ateliê, diante do cavalete, com pincel e paleta à mão. Não se trata de um auto-retrato no sentido realista do termo. Uma vez mais, Daumier soube perceber o que há de universal no momentâneo, de modo que se pode dizer que a obra apresenta não só o próprio Daumier, mas todos os pintores. Assim, também é permitido ampliar o significado dessa representação e dizer que Daumier não pintou apenas um artista em seu ambiente de trabalho, mas um homem que, investido de sua espada e de seu escudo, fixa seu

${ }^{41}$ Le long du vieux faubourg, où pendent aux masures / Les persiennes, abri des secrètes luxures, / Quand le soleil cruel frappe à traits redoublés / Sur la ville et les champs, sur les toits et les blés, // Je vais m'exercer seul à ma fantasque escrime, / Flairant dans tous les coins les hasards de la rime, / Trébuchant sur les mots comme sur les pavés, / Heurtant parfois des vers depuis longtemps rêvés. (Tradução de Ivan Junqueira: As flores do mal. Rio de Janeiro: Nova Fronteira, 1985, p. 319)

42 Quand, ainsi qu'un poète, il descend dans les ville, / Il ennoblit le sort des choses les plus viles, / Et s'introduit en roi, sans bruit et sans valets, / Dans tous les hôpitaux et dans tous les palais.

43 Uma versão encontra-se em Washington, na Phillips Collection, enquanto que a outra está em Williamstown (EUA), no Sterling and Francine Clark Art Institute. 
olhar sobre o adversário. É dessa maneira que se deve ver a obra de Daumier. Ele é o Dom Quixote que esgrima contra seus fantasmas. Assim como o poeta, ele se choca contra a realidade e desse confronto nasce a obra; do mal e do lixo a beleza é extraída.

Na dedicatória do Salão de 1846 (BAUDELAIRE, 1976, p. 415-417), Baudelaire, não sem ironia, correndo mesmo o risco de ser incompreendido, procura apaziguar a burguesia - ou aqueles dentre os burgueses que assim se deixarem conduzir - ao mesmo tempo que pretende causar a revolta daqueles que não compactuam com essa classe. Quando os retratos-charges foram impressos, causaram - ou ao menos poderiam ter causado - um efeito análogo. Ao corresponder ao gosto burguês, agradaram até mesmo alguns dos retratados - que acharam graça na brincadeira. Por outro lado, ao escancarar, em cada detalhe, os vícios e as fraquezas daqueles homens homens eternos -, fizeram com que os adversários da burguesia percebessem todos aqueles vícios e fraquezas e, por conseguinte, desempenharam o papel de agentes da revolta. O Ratapoil ${ }^{44}$ diverte o burguês - seja ele republicano, orleanista ou legitimista -, que ri do exagero do agente explorador da boa fé do povo. Quanto à classe oposta, esta vê os fatos como que iluminados. Uma obra que retrate um operário pronto para lutar em uma insurreição desperta o horror do burguês e, ao tentar educar e incitar o proletário, apenas gera nesse a simpatia - a qual, quase sempre, não se transforma em ação. 0 Ratapoil, o homem do subproletariado em traje burguês, é a contradição que faz sorrir um lado ao mesmo tempo que desperta o ódio no outro. Já no caso dos fugitivos, as peças dessas variações fazem com que os defensores da ordem exultem de alegria ao ver os criminosos que batem em retirada - como Luís Filipe se sentiu aliviado com a morte de Lafayette (Enterrado Lafayette!... Trapaça, meu velho! [LD 134]) - e, simultaneamente, provocam o proletariado. É como se lhe perguntassem: "Então é isso? esse é o teu fim?"

Desse modo, pode-se concluir que se o realismo pecava pela falta de imaginação e pela submissão à natureza, se a arte de caráter didático não produzia frutos, se a fantasia de Delacroix não bastava, e se em Guys, o pintor da vida moderna, não havia ambigüidades, contradições ou contrastes ${ }^{45}$

44 Escultura feita por Daumier em março de 1851 (RAGAZZI, 2004, p. 67-71) e moldada em gesso - presumivelmente a pedido do próprio Daumier - por Geoffroy-Dechaume (1816-1892). Representa o agente de Luís Napoleão - retirado das camadas mais necessitadas da população - encarregado de conquistar simpatizantes para o futuro imperador.

45 Todavia, é possível interpretar a pintura da moda de Guys como correspondente ao gesto de des Esseintes para com o jovem pobre de Às avessas (HUYSMANS, 1987, p. 101-105). Uma pequena amostra do prazer é oferecida e, logo a seguir, é negada. Em ambos os casos pode-se esperar uma reação por parte daquele que se vê privado dos prazeres materiais. No episódio de des Esseintes nada aconteceu; o rapaz não se tornou um criminoso e o dândi-artista viu-se traído. De fato, esse é o resultado na maioria das vezes, pois que o mecanismo artístico somente se converterá em ação se o público, por conta própria, completar o exercício proposto. 
então o silêncio de Baudelaire em relação à obra de pintura e escultura de Daumier deve ser entendido como admiração e respeito. Isso porque Daumier possui os elementos ambicionados pela estética baudelairiana. Em sua obra, encontra-se o contraste e percebe-se a parcela do eterno que foi abstraída do transitório, a beleza retirada do Mal. A memória é seu modelo, e suas criações são repletas de fantasia. A única ressalva fica por conta do compromisso com a moda, com as coisas materiais. Daumier se aproxima disso em sua obra gráfica, na qual se vê o Mal pintado com fantasia, é certo, mas sem beleza. Quanto à pintura e à escultura, o compromisso com o belo ideal e com a figura da bela mulher, bem vestida e maquilada, foi sempre repudiado por Daumier. ${ }^{46}$

Se Daumier hesita ou parece insatisfeito com sua obra, Baudelaire, ao se manter calado, aprova essa obra e como que espera por algo - talvez o amadurecimento de Daumier, talvez o seu próprio - para se pronunciar.

\section{RESUMO}

A amizade mantida entre o escritor e crítico Charles Baudelaire e o pintor, escultor e caricaturista Honoré Daumier é pouco conhecida e, sobretudo, sua importância é pouco considerada. Neste artigo essa amizade será avaliada para que se evidencie a grandeza de Daumier, à época relegado por muitos e, ao mesmo tempo, profundamente respeitado por outros. Assim, a partir de alguns pontos fundamentais inerentes ao método de crítica de Baudelaire, procurar-se-á compreender o juízo de Baudelaire em relação à obra de pintura e escultura de Daumier. Se Baudelaire se pronunciou, em relação a Daumier, apenas no que diz respeito a sua obra como caricaturista, o silêncio do crítico em relação à obra de pintura e escultura de Daumier não pode ser julgado como esquecimento ou indiferença; em vez disso, é preciso extrair algum significado desse silêncio.

Palavras-chave: Baudelaire, Charles, 1821-1867; Daumier, Honoré, 1808-1879; crítica de arte.

46 Esse fato, naturalmente, vai contra os propósitos de Baudelaire. De todo modo, com essa postura Daumier possibilita uma outra via para a arte. Como notou Lionello Venturi, não se encontra em Daumier a figura "da bela mulher, a qual outra coisa não teria sido senão um compromisso com o belo ideal, o qual, por mérito essencial de Daumier, foi excluído da arte moderna" (VENTURI, 1949, p. 122). 


\begin{abstract}
The friendship maintained between the writer and critic Charles Baudelaire and the painter, sculptor and caricaturist Honoré Daumier is just a little known and especially its importance is underestimated. In this article this friendship will be considered to evidence Daumier's great ability, at that time relegated by many people and deeply respected by a few others. In this manner, from some fundamental points inherent in Baudelaire's critical method, we will try to understand Baudelaire's judgement considered in relation to Daumier's pictorial and sculptural work. If Baudelaire pronounced his opinion just related to Daumier's graphic work, the silence of the critic concerning the artist's pictorial and sculptural work can not be judged as forgetfulness or indifference; on the contrary, we must extract some meaning from this silence.
\end{abstract}

Key-words: Baudelaire, Charles, 1821-1867, Daumier, Honoré, 1808-1879, art critic.

\title{
REFERÊNCIAS
}

BAUDELAIRE, Charles. Correspondance. T. 1-2. Paris: Gallimard, 1973.

. CEuvres complètes. T. 1. Paris: Gallimard, 1975.

. Euvres complètes. T. 2. Paris: Gallimard, 1976.

BENJAMIN, Walter. Obras escolhidas III. Charles Baudelaire. Um lírico no auge do capitalismo. São Paulo: Brasiliense, 1994.

CHAMPFLEURY, Jules Husson (Dit.). Histoire de la caricature moderne. Paris: E. Dentu, 1878. (1865)

CLARETIE, Jules. Peintres et sculpteurs contemporains. Première série. Artistes décédés de 1870 à 1880. Paris: Librairie des Bibliophiles, 1882.

DAUMIER. Arts et Livres de Provence,. Marseille: 1948. Numéro spécial. 8.

DELACROIX, Eugène. Delacroix: Journal (1822-1863). (Collection Le monde en 10 18). Paris: Union Générale d'Éditions, 1963.

DELTEIL, Loÿs (LD). Le peintre-graveur illustré (XIXe et XXe siècles). T. 20-29. Paris: Chez l'acteur, 1925-26.

FOCILLON, Henri. Deux visionnarires: Balzac et Daumier. In: De Callot à Lautrec. Paris: La bibliothèque des arts, 1957, p. 95-118.

. Honoré Daumier. In: Maîtres de l'estampe. Paris: Flammarion, 1969, p. 143-162.

HUYSMANS, J. K. (1884). Às avessas. São Paulo: Companhia das Letras, 1987.

LA CARICATURE Morale, Religieuse, Littéraire et Scénique, n. 78, 26 avr. 1832. 
LOYRETTE, Henri; PANTAZZI, Michael; LE MEN, Ségolène et al. Daumier 1808 - 1879. Paris: Réunion des Musées Nationaux, 1999.

MARCEAU, Henri; ROSEN, David. A terracotta by Daumier. The Journal of the Walters Art Gallery, Baltimore, v. 11, 1948, p. 76-82.

OEHLER, Dolf. (1979). Quadros parisienses. Estética antiburguesa. 1830 - 1848. São Paulo: Companhia das Letras, 1997.

RAGAZZI, Alexandre. Daumier escultor. Correspondências com a pintura e a obra gráfica. Campinas, 2004, 161 f. Dissertação (Mestrado em História da Arte) - Universidade Estadual de Campinas.

VENTURI, Lionello. Pittori moderni. Firenze: Edizioni U, 1949. 